\title{
Genetic Variants and Related Biomarkers in Sporadic Alzheimer's Disease
}

\author{
Rita Guerreiro $\cdot$ Jose Bras · Jamie Toombs • \\ Amanda Heslegrave • John Hardy • \\ Henrik Zetterberg
}

Published online: 24 December 2014

(c) The Author(s) 2014. This article is published with open access at Springerlink.com

\begin{abstract}
From a neuropathological perspective, elderly patients who die with a clinical diagnosis of sporadic Alzheimer's disease (AD) are a heterogeneous group with several different pathologies contributing to the $\mathrm{AD}$ phenotype. This poses a challenge when searching for low effect size susceptibility genes for AD. Further, control groups may be contaminated by significant numbers of preclinical $\mathrm{AD}$ patients, which also reduces the power of genetic association studies. Here, we discuss how cerebrospinal fluid and imaging biomarkers can be used to increase the chance of finding novel susceptibility genes and as a means to study the functional consequences of risk alleles.
\end{abstract}

Keywords Cerebrospinal fluid · Imaging biomarkers · Novel susceptibility genes $\cdot$ Risk alleles

This article is part of the Topical Collection on Neurogenetics and Psychiatric Genetics.

R. Guerreiro $(\bowtie) \cdot$ J. Hardy

Department of Molecular Neuroscience, UCL Institute

of Neurology, 1 Wakefield Street (1st Floor),

London WC1N 1PJ, UK

e-mail: r.guerreiro@ucl.ac.uk

J. Bras $\cdot$ J. Toombs $\cdot$ A. Heslegrave $\cdot$ H. Zetterberg

Department of Molecular Neuroscience, UCL Institute

of Neurology, Queen Square, London WC1N 3BG, UK

\section{H. Zetterberg}

Clinical Neurochemistry Laboratory, Department of Psychiatry and Neurochemistry, Institute of Neuroscience and Physiology, The Sahlgrenska Academy at University of Gothenburg, Mölndal, Sweden

\section{Introduction}

Alzheimer's disease (AD) is considered the most common form of dementia, but still lacks effective preventive or therapeutic interventions. This is probably partially due to an incomplete understanding of $\mathrm{AD}$ aetiology and the possible confounding factors associated with its genotypic and phenotypic heterogeneity. The disease was named after Alois Alzheimer, who in the early 20th century described cases of "presenile dementia", with neuropathological features characterized by gross cerebral atrophy, extracellular senile plaques and intracellular neurofibrillary tangles. Although there were some early doubts about the distinction between early-onset and late-onset dementia, during the first half of the 20th century, AD was mainly thought of as a rare disease that affected middle-aged people, while most elderly people with dementia were considered to have "senile dementia", caused primarily by age-related vascular pathology [1]. AD was only recognized as an important cause of dementia in elderly people after several autopsy studies in the 1950s to 1970s had noted the high prevalence of AD-like neuropathology in patients with "senile dementia" $[2,3]$.

During the 1980s to 1990s, breakthroughs in biochemistry and genetics laid the basis for strong hypotheses about the cause of $\mathrm{AD}$, which first led to the development of the symptomatic treatments that are currently available [4], and second to clinical trials of therapeutic approaches targeted against amyloid $\beta(\mathrm{A} \beta)$, the major component of senile plaques and a potential driver of the disease $[5,6]$.

Several lines of data point to significant pathological and clinical heterogeneity among clinically diagnosed AD patients. Many autopsy studies have shown that most elderly patients with dementia have mixed pathologies, with AD-like pathology combined with other brain 
pathologies, such as Lewy bodies, white matter disease, angiopathy, or TDP-43 inclusions [7-10]. After AD, the most common dementia form is dementia with Lewy bodies (DLB), characterized by the accumulation of $\alpha$-synuclein aggregates and cognitive impairment that is not dominated by memory decline, but rather executive and visuospatial problems, and a high frequency of hallucinations and delusions. About 10-40\% of AD patients have concomitant Lewy bodies [11-13], which likely affects the clinical course of $\mathrm{AD}$, since $\mathrm{AD}$ patients with Lewy bodies have faster cognitive decline than those without Lewy bodies [14]. So far, it remains very difficult to identify Lewy body pathology in $\mathrm{AD}$ patients in vivo. Another very common cause of dementia is cerebrovascular disease. Vascular cognitive impairment defines alterations in cognition, ranging from subtle deficits to full-blown dementia, attributable to cerebrovascular causes. Often coexisting with $\mathrm{AD}$, mixed vascular and neurodegenerative dementia has actually been proposed as the leading cause of agerelated cognitive impairment and dementia [15]. Biomarker changes that associate with cerebrovascular disease, e.g., white matter changes on computed tomography or magnetic resonance imaging (MRI) of the brain and elevated CSF levels of neurofilament light, are common in elderly patients with clinical AD [16], and it is possible that the dementia syndrome in some of these individuals is not driven by $\mathrm{AD}$ pathology but rather deficits in the cerebrovasculature. Susceptibility genes for AD pathology will not be found in these patients.

Here, we share our view on what could be gained by performing genetic studies on patients with more extensive information on underlying pathologies using different forms of biomarkers. The focus is on AD-related pathologies but the reasoning should be relevant also to other neurodegenerative diseases.

\section{Biomarkers for AD Pathology}

During the last two decades, biomarker tools have been developed, which allow researchers and clinicians to identify AD-like pathology in vivo, even years before the first symptoms emerge. Cerebrospinal fluid (CSF) levels of total tau and phospho-tau are positively correlated to neurodegeneration and neurofibrillary tangle pathology, whereas CSF levels of aggregation-prone 42 amino acid long $A \beta(A \beta 42)$ are negatively correlated to plaque pathology [17]. A recent meta-analysis assessing studies in which clinical criteria were used suggests that the combination of CSF tau and A $\beta$ markers shows a sensitivity of $84 \%(76-90 \%)$ and a specificity of $71 \%(59-81 \%)$ for $\mathrm{AD}$ both in dementia and mild cognitive impairment stages of the disease [18]. Further, plaque pathology can be visualized using amyloid positron emission tomography (PET) [19], and tau PET is a more recent potential biomarker tool to monitor tangle pathology [20]. The first biomarker changes indicating $A \beta$ build-up in the brain appear 10-20 years before clinical onset of the disease with $A \beta$ markers preceding tau markers by $5-10$ years [21, 22-]. This puts $A \beta$ before tau in regards to the sequence of events during the disease process. However, much remains to be learnt regarding what factors may initiate $A \beta$ deposition.

\section{Genetics of Sporadic AD}

\section{APP and PSEN Mutations}

The causative roles of mutations in the amyloid $\beta$ precursor protein (APP) and presenilin (PSEN1 and PSEN2; encoding the active site of $\gamma$-secretase that produces $\mathrm{A} \beta$ from APP with most mutations resulting in qualitative changes in APP-processing which promote cerebral $\beta$-amyloidosis [23]) genes in familial $\mathrm{AD}$ have long been recognized [24]. However, genetic analysis of late-onset sporadic AD has surprisingly revealed that these mutations are also pathogenic in some cases of late-onset $\mathrm{AD}$ and CSF biomarkers have been used as endophenotypes to detect mutations in the genes known to harbour AD-causative mutations $[25,26]$. The Swedish APP mutation causes AD because it makes the protein a better substrate for BACE1 (the major $\beta$-secretase responsible for cleaving APP in the N-terminal part of the A $\beta$ domain making the remaining stub a $\gamma$-secretase substrate) and thus more APP is metabolized along the amyloidogenic pathway and more $A \beta$ is produced [27]. In a recent study, Jonsson and colleagues [28•] noted that a specific mutation in APP, which previously had been identified to be located close to the $\beta$-secretase site [29], made it a worse substrate for BACE1 and correspondingly was associated with lower $A \beta$ production and lower risk of $\mathrm{AD}$. This observation, if replicated, supports the $\mathrm{A} \beta$ cascade hypothesis and also BACE1 inhibition as a valid target for AD therapy. Autosomal dominant mutations that cause familial $\mathrm{AD}$ without effect on $A \beta$ metabolism have not yet been reported. The study of $\mathrm{AD}$ biomarkers in these familial cases has been essential to establish the timeline of pathological events in the disease, and in particular, to support the existence of a long preclinical stage [22•, 30].

A recent multicenter, longitudinal study of CSF in families with autosomal dominant $\mathrm{AD}$ mutations revealed a clear transition of CSF markers over-time with reduced concentrations of CSF A $\beta 1-42$ (associated with the presence of amyloid plaques) and elevated concentrations of CSF markers of neurofibrillary tangles and neuronal injury/ 
death in asymptomatic mutation carriers 10-20 years before their estimated age at symptom onset. The longitudinal assessment also revealed an over-time decrease in the concentration of injury-related markers after symptom onset, suggesting a slowing of acute neurodegenerative processes with symptomatic disease progression [22•].

\section{APOE}

The association of the apolipoprotein $E$ (APOE) $\varepsilon 4$ allele with $\mathrm{AD}$ is strong (odds ratios ranging from 3 to 10 in different studies [31•]) and undisputed. ApoE is the major carrier of cholesterol in the CNS and has also important roles in $\mathrm{A} \beta$ metabolism, aggregation, and deposition. Increased plaque deposition has been observed in $A P O E$ $\varepsilon 4$-positive individuals and in $A P O E$ \&4 knock-in animal models of cerebral $\beta$-amyloidosis [32-34]. ApoE binds $A \beta$ but the apoE4 isoform has a lower affinity than apoE3, and it appears that at least part of the association of APOE $\varepsilon 4$ with $A \beta$ plaque pathology is related to apoE4 being less efficient in clearing $A \beta$ from the brain parenchyma [35]. This may explain why cognitively healthy people with $A P O E \& 4$ have biomarker signs of $A \beta$ pathology at an earlier age than people lacking the $A P O E \& 4$ allele (especially compared to people carrying the $A P O E$ \&2 allele) [36].

In a genome-wide study, the APOE $\varepsilon 4$ genotype was the strongest single-genetic factor associated with CSF ApoE protein levels. ApoE CSF, but not plasma, levels were found to significantly associate with CSF A $\beta 42$ levels independently of the $A P O E \& 4$ genotype, and suggesting that ApoE levels in CSF may be a useful endophenotype for $\mathrm{AD}$ [37]. However, in contrast, $A P O E$ \&4 does not interact with age to produce biomarker signs of axonal degeneration (increased CSF T-tau) or tangle pathology (increased CSF P-tau), supporting the view that APOE $\varepsilon 4$ does not have a primary effect on these aspects of $\mathrm{AD}$ pathology (alternatively, these biomarkers may have too low sensitivity to identify such effects).

One study [38] has shown an interesting interaction effect between $A P O E$ and $\mathrm{A} \beta 1-42$ in the CSF of $A P O E \varepsilon 4$ carriers. Homo- and heterozygotes of the $A P O E \& 4$ allele had significantly lower detectable $A \beta 42$ concentrations than APOE \&3 homozygotes. Although the exact mechanism is not understood, the implication is for matrix composition of these (and potentially other) proteins in CSF to impact the measurement of corner-stone biomarkers such as $\mathrm{A} \beta 42$, and perhaps aid exploration of pathorelevant physiological processes. As such there may be considerable utility for genetic and proteomic characterisation of $\mathrm{AD}$ patients and research subjects.

Exactly how the ApoE4 isoform promotes AD is still unclear, and conflicting results present in the literature support both a loss of positive or gain of negative functions of the protein. The role of ApoE in AD becomes even more complex when considering the recent report of a patient with a rare form of severe dysbetalipoproteinemia who was homozygous for an ablative $A P O E$ frameshift mutation. As expected, the patient had exceptionally high cholesterol content with profound lipoprotein metabolism dysregulation. However, this 40-year-old patient presented surprisingly normal neurological-related features (normal vision, normal cognitive, neurological, and retinal functions, normal findings on brain magnetic resonance imaging, and normal CSF levels of $A \beta$ and tau proteins) [39]. It would have been very interesting to determine the CSF lipidation profile of this patient, especially to assess the possibility of compensation by other apolipoproteins, and further follow-up will reveal if age-related neurological deficits will appear.

\section{Other Susceptibility Genes}

Genome-wide association studies (GWAS) identify common loci (typically frequencies of 10-50\%), which have low to modest effects on risk (typically with odds ratios in the 1.1-2.0 range). Over the last 5 years, this approach has begun to yield large numbers of risk loci, and this harvest continues as study pooling is ongoing and as larger numbers of samples are collected [40••]. The utility of these studies in terms of predicting who will develop disease is currently modest. However, their larger importance is that they may identify pathways and processes in which genetic variability affects disease risk. So far, GWAS have identified 3 such pathways: (i) endosomal vesicle recycling (BIN1, PICALM and SORL1), (ii) the innate immune system (TREM2, CRI and $C L U$ ) and (iii) genes related to cholesterol metabolism $(A B C A 7, C L U)$ [41]. It is not yet possible to definitively relate these pathways directly to each other or to $A \beta$ but they resonate well with recent CSF biomarker data showing links between $\mathrm{A} \beta$ pathology and/ or $\mathrm{AD}$ and CSF levels of endosomal/lysosomal network proteins, and proteins related to microglial activation and synaptic function or integrity [42-45].

\section{Can Biomarkers Help us Finding More Risk Genes for Sporadic AD?}

There has been a recent surge in interest in the use of endophenotypes in research on psychiatric and neurodegenerative diseases, $\mathrm{AD}$ in particular. The concept was introduced by Gottesman and Shields to reduce the harmful influence of poor accuracy in the clinical diagnosis of psychiatric and neurological diseases on the power of genetic association studies [46], which is a major problem in $\mathrm{AD}$ research. In addition, the identification of disease 
endophenotypes offers the prospect of creating experimental models relevant to human pathophysiology, which will be suitable for experimental approaches and greatly facilitate the development and screening of novel therapeutics. Endophenotypes may be described as internal phenotypes that lie on the pathway between genes and disease. Fundamental to the concept is the assumption that variation in an endophenotype will depend upon variation in fewer genes than the more complex disease phenotype and therefore be more tractable to genetic analysis [46]. The combination of clinical and biomarker information (as opposed to definition based on clinical data only) to define cases and controls in genetic association studies increases the power of these analyses. This could be inferred when $A P O E \& 4$ was found to present a stronger association with $\mathrm{AD}$ when clinical criteria incorporated biomarker information, and when genetic associations were replicated using much smaller sample sizes when compared to the original associations, by means of defining cases and controls according to CSF biomarker profiles [31•].

In $\mathrm{AD}, \mathrm{CSF}$ and imaging biomarkers have been used as endophenotypes in several genetic studies, both to increase the chance of finding novel susceptibility genes and as a means to study the functional consequences of risk alleles. These studies have been closely tied with genetic technology developments, moving from analyses of individual genetic variants or genes to genome-wide approaches (Fig. 1).

When studying specific variants/genes, these were usually chosen given an a priori biological or aetiological association with disease. This was the case when Kauwe et al. identified a gene-physiological environment interaction between MAPT common single-nucleotide polymorphisms (SNPs) and $\mathrm{A} \beta$ deposition through the evaluation of the role of these SNPs in CSF tau/ptau levels [50]. An analogous approach was used to study genes involved in the complement system. Daborg et al. chose to study the complement system because of its involvement in both physiological and $\mathrm{AD}$ synapse elimination. The authors studied 4 SNPs in different genes $(C 2, C 3, C F B$ and $C R 1$ ) and although no significant associations were found with $A D$ risk, potential associations between SNPs in $C 2$ and $C F B$ were identified in relation to CSF tau levels and Mini-Mental State Examination (MMSE) scores [51].

Cruchaga and colleagues studied 384 SNPs selected from genes known to code for the most relevant tau kinases, phosphatases, and in other genes implicated in other posttranslational modifications of tau, or tau degradation. The authors were able to detect a SNP (rs1868402) in PPP3Rl associated with CSF P-tau181 levels. This variant showed a strong association with the rate of decline in $\mathrm{AD}$ patients, but no association was detected with $\mathrm{AD}$ risk or age at onset of the disease [49]. By taking a genome-wide approach, the same group was able to identify 4 genomewide significant signals associated with CSF tau levels (including tau and ptau): APOE; rs9877502 located at 3q28 between GEMC1 and OSTN; rs514716 located at 9p24.2 within GLIS3; and rs6922617 at 6p21.1 within the TREM gene cluster [52•]. A clear signal that this is a valid approach to identify novel risk variants for a complex disease like Alzheimer's is the fact that 3 (APOE, 3q28 and $6 \mathrm{p} 21.1$ ) of the 4 genome-wide significant loci identified had also been independently associated with the disease $[53,54,55 \bullet, 56 \bullet \cdot]$.

To expand the use of endophenotypes beyond CSF A $\beta 42$ and tau, Kauwe et al. studied the CSF levels of 59

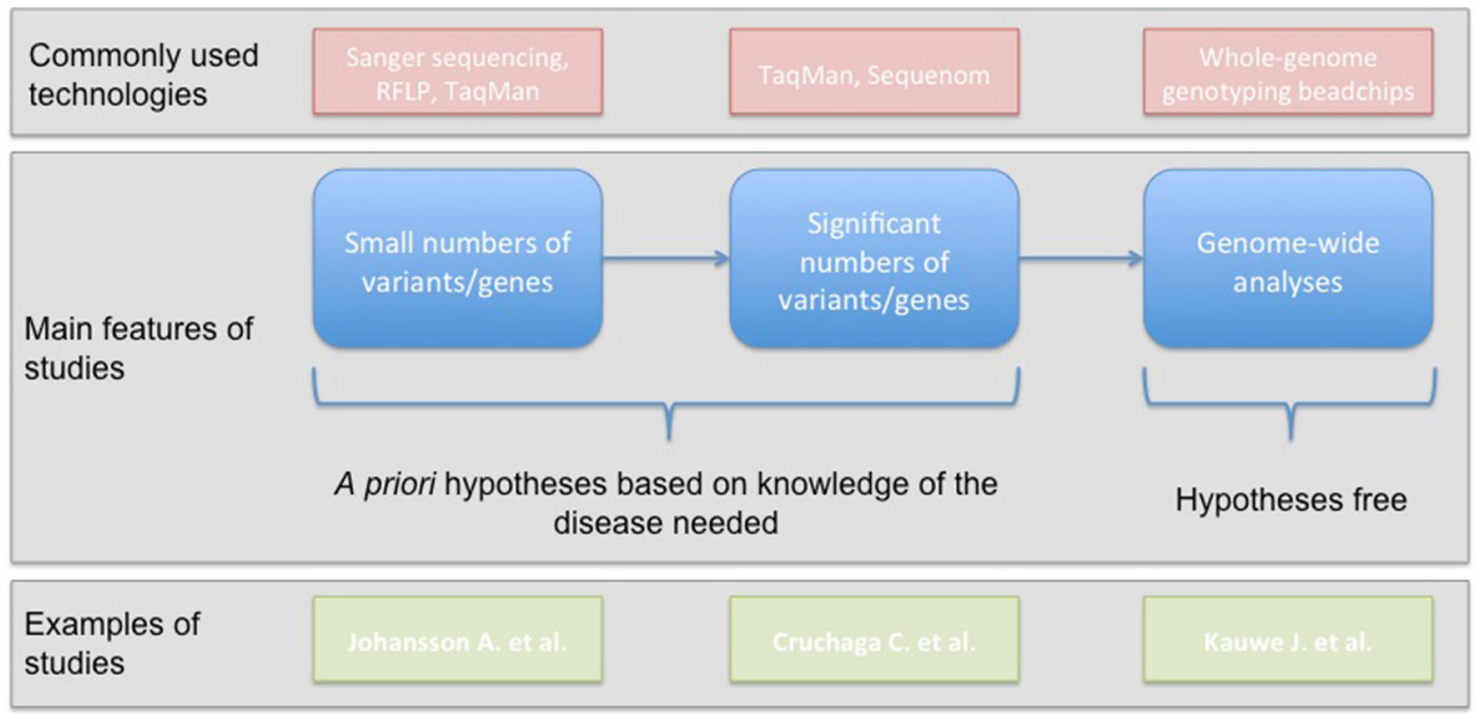

Fig. 1 Evolution of genetic studies based on endophenotype associations in Alzheimer's disease. Examples of studies [47, 48•, 49] 
AD-related proteins in a GWAS study [48•]. They identified significant genetic associations with CSF levels of 5 proteins involved in amyloid processing and pro-inflammatory signalling: Angiotensin-converting enzyme (ACE), Chemokine (C-C motif) ligand 2 (CCL2), Chemokine (C-C motif) ligand 4 (CCL4), Interleukin 6 receptor (IL6R) and Matrix metalloproteinase-3 (MMP3), suggesting mechanisms for genetic control of CSF and plasma levels of these disease-related proteins. Interestingly, the SNPs found to be significantly associated in $A C E$ and $M M P 3$ also showed association with AD risk [48•].

\section{Can Biomarkers Help us to Characterize the Functional Mechanisms of each Associated Loci in AD?}

One of the limitations of case-control GWAS is the fact that generally only haplotype tagging markers are identified by this methodology. When comparing frequencies of genotypes between large numbers of cases and controls, it would be very difficult to do this for every single variant in the genome. To overcome this, GWAS platforms are based on haplotypes and only SNPs tagging each haplotype are analysed. Although this approach eases the burden of comparative testing, it also prevents the identification of specific disease-associated variants, as these can be in linkage disequilibrium (LD) with the genome-wide hit identified. An essential follow-up step to the identification of GWAS significant loci for a disease is the characterization of the functional mechanisms by which the associated variants influence the risk for disease. Kauwe et al. used an endophenotype-based approach to attempt to generate biological hypotheses of risk mechanism for BINI, CLU, CRI and PICALM. To accomplish this, the authors sampled common variation in these genes, genotyping 355 variants in over 600 individuals for whom measurements of CSF A $\beta 42$ and P-tau181 had been obtained. Although this was a well-designed study, no associations between SNPs in these genes and CSF A $\beta 42$ or P-tau181 levels were found in the studied sample, suggesting that the associated variants at these loci do not affect risk via a mechanism resulting in a strong additive effect on CSF levels of A $\beta 42$ or P-tau181 [57]. In a study using family-based and case-control designs, Schjeide et al. performed an analogous analysis of 5 variants in $C L U, C R 1$ and PICALM. The authors identified a significant effect of rs541458 in PICALM on CSF A $\beta 42$ levels [58]. With the same goal, Elias-Sonnenschein et al. studied 36 SNPs in 25AD-related genes in a cohort of 222 Finish AD patients for which CSF biomarker levels were available. They identified several significant associations: $A P O E$ \&4, CLU rs11136000, and MS4A4A rs2304933 correlated with significantly decreased CSF A $\beta 42$; at an uncorrected level PPP3RI rs1868402 and MAPT rs2435211 were related with increased T-tau; SORL1 rs73595277 and MAPT rs16940758 were associated with increased P-tau [59].

Altogether, these studies clearly point to the need of structured, well-powered analyses. The application of this approach to other loci, the increase in the number of samples studied and the use of replication cohorts will probably allow for a deeper characterization of these associations.

\section{Conclusions}

The integration of genetic results with biomarkers is essential for advancing the research into $\mathrm{AD}$ and other complex disorders. Genetic studies clearly have an extreme potential for the identification of novel biomarkers for $\mathrm{AD}$, but biomarkers are also essential for the guiding of genetic studies both in familial and sporadic forms of the disease. The use of endophenotypes in GWAS adds a layer of information to this type of study because it directly associates with specific disease-related biological mechanisms. The computational ability to test for associations in wellstructured studies at a genome-proteome-wide level will most likely reveal novel molecular interactions important for the risk and progression of $\mathrm{AD}$.

Acknowledgments We wish to thank colleagues and patients and their families for generating the extensive literature that was reviewed here. We gratefully acknowledge the support of the Leonard Wolfson Experimental Neurology Centre, Alzheimer's Research UK, Alzheimer's Society, the NIHR Queen Square Dementia BRU, the Swedish Research Council and the Knut and Alice Wallenberg Foundation.

Disclosure R Guerreiro, J Bras, J Toombs, and A Heslegrave all declare no conflicts of interest. J Hardy has received a speaker honorarium from Eli Lily and Merck; and consulting fees from Eisai and Cytox. H. Zetterberg declares no conflicts of interest.

Human and Animal Rights and Informed Consent All studies by the authors involving animal and/or human subjects were performed after approval by the appropriate institutional review boards. When required, written informed consent was obtained from all participants.

Open Access This article is distributed under the terms of the Creative Commons Attribution License which permits any use, distribution, and reproduction in any medium, provided the original author(s) and the source are credited.

\section{References}

Papers of particular interest, published recently, have been highlighted as:

- Of importance

•• Of major importance 
1. Förstl H. Contributions of German neuroscience to the concept of Alzheimer disease. In: Whitehouse PJ, Maurer K, Ballenger JF, editors. Concepts of Alzheimer disease: biological, clinical, and cultural perspectives. Baltimore: The Johns Hopkins University Press; 2000.

2. Neumann MA, Cohn R. Incidence of Alzheimer's disease in large mental hospital; relation to senile psychosis and psychosis with cerebral arteriosclerosis. AMA Arch Neurol Psychiatry. 1953; 69(5):615-36.

3. Tomlinson BE, Blessed G, Roth M. Observations on the brains of demented old people. J Neurol Sci. 1970;11(3):205-42.

4. Whitehouse PJ, Price DL, Struble RG, Clark AW, Coyle JT, Delon MR. Alzheimer's disease and senile dementia: loss of neurons in the basal forebrain. Science. 1982;215(4537):1237-9.

5. Hardy J, Allsop D. Amyloid deposition as the central event in the aetiology of Alzheimer's disease. Trends Pharmacol Sci. 1991; 12(10):383-8.

6. Hardy JA, Higgins GA. Alzheimer's disease: the amyloid cascade hypothesis. Science. 1992;256(5054):184-5.

7. Schneider JA, Arvanitakis Z, Bang W, Bennett DA. Mixed brain pathologies account for most dementia cases in communitydwelling older persons. Neurology. 2007;69(24):2197-204.

8. James BD, Bennett DA, Boyle PA, Leurgans S, Schneider JA. Dementia from Alzheimer disease and mixed pathologies in the oldest old. JAMA. 2012;307(17):1798-800.

9. Davidson YS, Raby S, Foulds PG, Robinson A, Thompson JC, Sikkink S, Yusuf I, Amin H, DuPlessis D, Troakes C, et al. TDP43 pathological changes in early onset familial and sporadic Alzheimer's disease, late onset Alzheimer's disease and Down's syndrome: association with age, hippocampal sclerosis and clinical phenotype. Acta Neuropathol. 2011;122(6):703-13.

10. Toledo JB, Cairns NJ, Da X, Chen K, Carter D, Fleisher A, Householder E, Ayutyanont N, Roontiva A, Bauer RJ, et al. Clinical and multimodal biomarker correlates of ADNI neuropathological findings. Acta Neuropathol Commun. 2013;1(1):65.

11. Jellinger KA, Attems J. Prevalence and pathology of dementia with Lewy bodies in the oldest old: a comparison with other dementing disorders. Dement Geriatr Cogn Disord. 2011;31(4):309-16.

12. Hansen LA, Masliah E, Galasko D, Terry RD. Plaque-only Alzheimer disease is usually the lewy body variant, and vice versa. J Neuropathol Exp Neurol. 1993;52(6):648-54.

13. Schneider JA, Arvanitakis Z, Leurgans SE, Bennett DA. The neuropathology of probable Alzheimer disease and mild cognitive impairment. Ann Neurol. 2009;66(2):200-8.

14. Olichney JM, Galasko D, Salmon DP, Hofstetter CR, Hansen LA, Katzman R, Thal LJ. Cognitive decline is faster in Lewy body variant than in Alzheimer's disease. Neurology. 1998;51(2):351-7.

15. Iadecola C. The pathobiology of vascular dementia. Neuron. 2013;80(4):844-66.

16. Wallin A, Ohrfelt A, Bjerke M. Characteristic clinical presentation and CSF biomarker pattern in cerebral small vessel disease. J Neurol Sci. 2012;322(1-2):192-6.

17. Zetterberg H, Lautner R, Skillback T, Rosen C, Shahim P, Mattsson N, Blennow K. CSF in Alzheimer's disease. Adv Clin Chem. 2014;65:143-72.

18. Bloudek LM, Spackman DE, Blankenburg M, Sullivan SD. Review and meta-analysis of biomarkers and diagnostic imaging in Alzheimer's disease. J Alzheimers Dis. 2011;26(4):627-45.

19. Mathis CA, Mason NS, Lopresti BJ, Klunk WE. Development of positron emission tomography beta-amyloid plaque imaging agents. Semin Nucl Med. 2012;42(6):423-32.

20. Jagust W. Time for tau. Brain. 2014;137(Pt 6):1570-1.

21. Buchhave P, Minthon L, Zetterberg H, Wallin AK, Blennow K, Hansson O. Cerebrospinal fluid levels of beta-amyloid 1-42, but not of tau, are fully changed already 5 to 10 years before the onset of Alzheimer dementia. Arch Gen Psychiatry. 2012;69(1):98-106.
22. - Fagan AM, Xiong C, Jasielec MS, Bateman RJ, Goate AM, Benzinger TL, Ghetti B, Martins RN, Masters CL, Mayeux R et al. Longitudinal change in CSF biomarkers in autosomal-dominant Alzheimer's disease. Sci Transl Med. 2014;6(226):226ra230. This study illustrates how the longitudinal study of biomarkers in autosomal-dominant Alzheimer's disease families can elucidate the patterns of biomarkers trajectories during the course of disease, with major implications for clinical trials.

23. Chavez-Gutierrez L, Bammens L, Benilova I, Vandersteen A, Benurwar M, Borgers M, Lismont S, Zhou L, Van Cleynenbreugel $\mathrm{S}$, Esselmann $\mathrm{H}$, et al. The mechanism of gamma-Secretase dysfunction in familial Alzheimer disease. EMBO J. 2012; 31(10):2261-74.

24. Guerreiro R, Bras J, Hardy J. SnapShot: genetics of Alzheimer's disease. Cell. 2013;155(4):968-968e961.

25. Cruchaga C, Haller G, Chakraverty S, Mayo K, Vallania FL, Mitra RD, Faber K, Williamson J, Bird T, Diaz-Arrastia R, et al. Rare variants in APP, PSEN1 and PSEN2 increase risk for AD in lateonset Alzheimer's disease families. PLoS One. 2012;7(2):e31039.

26. Kauwe JS, Jacquart S, Chakraverty S, Wang J, Mayo K, Fagan AM, Holtzman DM, Morris JC, Goate AM. Extreme cerebrospinal fluid amyloid beta levels identify family with late-onset Alzheimer's disease presenilin 1 mutation. Ann Neurol. 2007; 61(5):446-53.

27. Citron M, Teplow DB, Selkoe DJ. Generation of amyloid beta protein from its precursor is sequence specific. Neuron. 1995;14(3):661-70.

28. - Jonsson T, Atwal JK, Steinberg S, Snaedal J, Jonsson PV, Bjornsson S, Stefansson H, Sulem P, Gudbjartsson D, Maloney J et al. A mutation in APP protects against Alzheimer's disease and age-related cognitive decline. Nature. 2012;488(7409):96-9. The authors identified a rare variant in APP that protects against $A D$. If replicated, the results from this study can have important implications for the development of drug treatments for $A D$. These results also validate the amyloid cascade hypothesis and establish, for the first time, a link between familial early onset and sporadic late onset $A D$.

29. Peacock ML, Warren JT Jr, Roses AD, Fink JK. Novel polymorphism in the A4 region of the amyloid precursor protein gene in a patient without Alzheimer's disease. Neurology. 1993;43(6): 1254-6.

30. Bateman RJ, Xiong C, Benzinger TL, Fagan AM, Goate A, Fox NC, Marcus DS, Cairns NJ, Xie X, Blazey TM, et al. Clinical and biomarker changes in dominantly inherited Alzheimer's disease. N Engl J Med. 2012;367(9):795-804.

31. - Andreasson U, Lautner R, Schott JM, Mattsson N, Hansson O, Herukka SK, Helisalmi S, Ewers M, Hampel H, Wallin A et al. CSF biomarkers for Alzheimer's pathology and the effect size of APOE varepsilon4. Mol Psychiatry. 2014;19(2):148-9. The results from this study indicate that it is possible to increase the power of genetic association studies by combining clinical and biomarker data.

32. Bales KR, Liu F, Wu S, Lin S, Koger D, DeLong C, Hansen JC, Sullivan PM, Paul SM. Human APOE isoform-dependent effects on brain beta-amyloid levels in PDAPP transgenic mice. J Neurosci. 2009;29(21):6771-9.

33. Castellano JM, Kim J, Stewart FR, Jiang H, DeMattos RB, Patterson BW, Fagan AM, Morris JC, Mawuenyega KG, Cruchaga $C$, et al. Human apoE isoforms differentially regulate brain amyloid-beta peptide clearance. Sci Transl Med. 2011; 3(89):89ra57.

34. Reiman EM, Chen K, Liu X, Bandy D, Yu M, Lee W, Ayutyanont N, Keppler J, Reeder SA, Langbaum JB, et al. Fibrillar amyloid-beta burden in cognitively normal people at 3 levels of genetic risk for Alzheimer's disease. Proc Natl Acad Sci USA. 2009;106(16):6820-5. 
35. Deane R, Sagare A, Hamm K, Parisi M, Lane S, Finn MB, Holtzman DM, Zlokovic BV. apoE isoform-specific disruption of amyloid beta peptide clearance from mouse brain. J Clin Invest. 2008;118(12):4002-13.

36. Morris JC, Roe CM, Xiong C, Fagan AM, Goate AM, Holtzman DM, Mintun MA. APOE predicts amyloid-beta but not tau Alzheimer pathology in cognitively normal aging. Ann Neurol. 2010;67(1):122-31.

37. Cruchaga C, Kauwe JS, Nowotny P, Bales K, Pickering EH, Mayo K, Bertelsen S, Hinrichs A, Fagan AM, Holtzman DM, et al. Cerebrospinal fluid APOE levels: an endophenotype for genetic studies for Alzheimer's disease. Hum Mol Genet. 2012;21(20):4558-71.

38. Slemmon JR, Meredith J, Guss V, Andreasson U, Andreasen N, Zetterberg $\mathrm{H}$, Blennow K. Measurement of Abeta1-42 in cerebrospinal fluid is influenced by matrix effects. $\mathrm{J}$ Neurochem. 2012;120(2):325-33.

39. Mak AC, Pullinger CR, Tang LF, Wong JS, Deo RC, Schwarz JM, Gugliucci A, Movsesyan I, Ishida BY, Chu C, et al. Effects of the absence of apolipoprotein e on lipoproteins, neurocognitive function, and retinal function. JAMA Neurol. 2014;71(10):1228-36.

40. • Lambert JC, Ibrahim-Verbaas CA, Harold D, Naj AC, Sims R, Bellenguez C, DeStafano AL, Bis JC, Beecham GW, GrenierBoley B et al. Meta-analysis of 74,046 individuals identifies 11 new susceptibility loci for Alzheimer's disease. Nat Genet. 2013;45(12):1452-8. In this study the authors identifyed 11 new risk loci for Alzheimer's disease by using meta-analytical analyses in several $A D$ GWAS datasets.

41. Jones L, Holmans PA, Hamshere ML, Harold D, Moskvina V, Ivanov D, Pocklington A, Abraham R, Hollingworth P, Sims R, et al. Genetic evidence implicates the immune system and cholesterol metabolism in the aetiology of Alzheimer's disease. PLoS One. 2010;5(11):e13950.

42. Armstrong A, Mattsson N, Appelqvist H, Janefjord C, Sandin L, Agholme L, Olsson B, Svensson S, Blennow K, Zetterberg H, et al. Lysosomal network proteins as potential novel CSF biomarkers for Alzheimer's disease. Neuromol Med. 2013;. doi:10. 1007/s12017-013-8269-3.

43. Daborg J, Andreasson U, Pekna M, Lautner R, Hanse E, Minthon L, Blennow K, Hansson O, Zetterberg H. Cerebrospinal fluid levels of complement proteins C3, C4 and CR1 in Alzheimer's disease. J Neural Transm. 2012;119(7):789-97.

44. Mattsson N, Insel P, Nosheny R, Zetterberg H, Trojanowski JQ, Shaw LM, Tosun D, Weiner M. CSF protein biomarkers predicting longitudinal reduction of CSF beta-amyloid42 in cognitively healthy elders. Transl Psychiatry. 2013;3:e293.

45. Mattsson N, Tabatabaei S, Johansson P, Hansson O, Andreasson U, Mansson JE, Johansson JO, Olsson B, Wallin A, Svensson $\mathrm{J}$, et al. Cerebrospinal fluid microglial markers in Alzheimer's disease: elevated chitotriosidase activity but lack of diagnostic utility. Neuromolecular Med. 2011;13(2):151-9.

46. Gottesman II, Gould TD. The endophenotype concept in psychiatry: etymology and strategic intentions. Am J Psychiatry. 2003;160(4):636-45.

47. Johansson A, Katzov H, Zetterberg H, Feuk L, Johansson B, Bogdanovic N, Andreasen N, Lenhard B, Brookes AJ, Pedersen NL, et al. Variants of CYP46A1 may interact with age and APOE to influence CSF Abeta42 levels in Alzheimer's disease. Hum Genet. 2004;114(6):581-7.

48. • Kauwe JS, Bailey MH, Ridge PG, Perry R, Wadsworth ME, Hoyt KL, Staley LA, Karch CM, Harari O, Cruchaga C et al. GenomeWide Association Study of CSF Levels of 59 Alzheimer's Disease Candidate Proteins: significant associations with proteins involved in amyloid processing and inflammation. PLoS Genet. 2014;10(10):e1004758. This manuscript reports the first GWAS of $C S F$ levels of multiple $A D$ candidate proteins. Novel significant associations are reported suggesting mechanisms for genetic control of CSF and plasma levels of these disease-related proteins.

49. Cruchaga C, Kauwe JS, Mayo K, Spiegel N, Bertelsen S, Nowotny P, Shah AR, Abraham R, Hollingworth P, Harold D, et al. SNPs associated with cerebrospinal fluid phospho-tau levels influence rate of decline in Alzheimer's disease. PLoS Genet. 2010;6(9):e1001101.

50. Kauwe JS, Cruchaga C, Mayo K, Fenoglio C, Bertelsen S, Nowotny P, Galimberti D, Scarpini E, Morris JC, Fagan AM, et al. Variation in MAPT is associated with cerebrospinal fluid tau levels in the presence of amyloid-beta deposition. Proc Natl Acad Sci USA. 2008;105(23):8050-4.

51. Daborg J, Holmgren S, Abramsson A, Andreasson U, Zetterberg M, Nilsson S, Minthon L, Skoog I, Blennow K, Pekna M, et al. Complement gene single nucleotide polymorphisms and biomarker endophenotypes of Alzheimer's disease. J Alzheimers Dis. 2013;35(1):51-7.

52. - Cruchaga C, Kauwe JS, Harari O, Jin SC, Cai Y, Karch CM, Benitez BA, Jeng AT, Skorupa T, Carrell D et al. GWAS of cerebrospinal fluid tau levels identifies risk variants for Alzheimer's disease. Neuron. 2013;78(2):256-68. By performing a large GWAS for CSF tau levels, the authors of this study identified three genome-wide significant loci in Alzheimer's disease.

53. Lee JH, Cheng R, Santana V, Williamson J, Lantigua R, Medrano M, Arriaga A, Stern Y, Tycko B, Rogaeva E, et al. Expanded genomewide scan implicates a novel locus at 3q28 among Caribbean hispanics with familial Alzheimer disease. Arch Neurol. 2006;63(11):1591-8.

54. Hiltunen M, Mannermaa A, Thompson D, Easton D, Pirskanen M, Helisalmi S, Koivisto AM, Lehtovirta M, Ryynanen M, Soininen $\mathrm{H}$. Genome-wide linkage disequilibrium mapping of late-onset Alzheimer's disease in Finland. Neurology. 2001;57(9):1663-8.

55. • Jonsson T, Stefansson H, Steinberg S, Jonsdottir I, Jonsson PV, Snaedal J, Bjornsson S, Huttenlocher J, Levey AI, Lah JJ et al. Variant of TREM2 associated with the risk of Alzheimer's disease. N Engl J Med. 2013;368(2):107-16. In this study the authors used the integration of genotyping and next generation sequencing technologies to identify a rare variant in TREM2 that conferrs an increased risk for the development of Alzheimer's disease. This is currently the second strongest genetic risk factor for $A D$, after the E4 allele of APOE.

56. •• Guerreiro R, Wojtas A, Bras J, Carrasquillo M, Rogaeva E, Majounie E, Cruchaga C, Sassi C, Kauwe JS, Younkin S et al. TREM2 variants in Alzheimer's disease. $\mathrm{N}$ Engl $\mathrm{J}$ Med. 2013;368(2):117-27. In this study the authors used the integration of genotyping and next generation sequencing technologies to identify a rare variant in TREM2 that conferrs an increased risk for the development of Alzheimer's disease. This is currently the second strongest genetic risk factor for $A D$, after the E4 allele of $A P O E$.

57. Kauwe JS, Cruchaga C, Karch CM, Sadler B, Lee M, Mayo K, Latu W, Su'a M, Fagan AM, Holtzman DM, et al. Fine mapping of genetic variants in BIN1, CLU, CR1 and PICALM for association with cerebrospinal fluid biomarkers for Alzheimer's disease. PLoS One. 2011;6(2):e15918.

58. Schjeide BM, Schnack C, Lambert JC, Lill CM, Kirchheiner J, Tumani H, Otto M, Tanzi RE, Lehrach H, Amouyel P, et al. The role of clusterin, complement receptor 1 , and phosphatidylinositol binding clathrin assembly protein in Alzheimer disease risk and cerebrospinal fluid biomarker levels. Arch Gen Psychiatry. 2011;68(2):207-13.

59. Elias-Sonnenschein LS, Helisalmi S, Natunen T, Hall A, Paajanen T, Herukka SK, Laitinen M, Remes AM, Koivisto AM, Mattila KM, et al. Genetic loci associated with Alzheimer's disease and cerebrospinal fluid biomarkers in a Finnish casecontrol cohort. PLoS One. 2013;8(4):e59676. 